・编者按・

\title{
探索我国生态保护红线划定与监管
}

\author{
高吉喜* \\ (环境保护部南京环境科学研究所，南京 210042)
}

\section{Exploring the delineation and supervision of ecological protection red- lines in China}

Jixi Gao*

Nanjing Institute of Environmental Sciences, Ministry of Environmental Protection, Nanjing 210042

我国自然资源丰富, 生态系统类型多样, 但由 于长期的不合理开发利用，面临的形势日益严峻, 尤其是可支撑我国经济社会持续发展的生态安全 格局尚未形成, 这不仅威胁到生态环境的保护, 而 且直接危及到国民的生存和经济社会的可持续发 展(吕一河等, 2006)。为加强生态环境保护, 构建区 域生态安全格局, 2011年《国务院关于加强环境保 护重点工作的意见》(国发[2011]35号)中明确提出, 在重要生态功能区、陆地和海洋生态环境敏感区、 脆弱区等区域划定生态红线。这是我国首次提出 “划定生态红线”这一重要战略任务, 生态保护红线 (ecological protection redlines)也因此成为继“18亿 亩耕地红线”后又一条被提到国家层面的“生命 线”(李干杰, 2014)。

自从提出划定生态红线之后，社会各界对生态 红线的认知度逐步提高, 国家层面对划定并严守生 态保护红线也更加重视。中国共产党十八届三中全 会把划定生态保护红线作为改革生态环境管理体 制、推进生态文明制度建设的最重要举措之一, 新 修订的《环境保护法》也将划定生态保护红线写入 法律(环境保护部, 2015), 为生态保护红线划定和实 施提供了法律依据。2015年, 生态保护红线划定工 作又被列入我国生态文明建设的纲领性文件和实 施方案之中, 生态保护红线划定因而进入各级政府 实质性推进阶段。

然而, 生态保护红线的划定和实施毕竟是一项 新的工作, 从生态保护红线的概念、内涵界定, 到
类型确定，以及划定后的实施与管理都面临一系列 问题需深入研究、探索和实践。有鉴于此, 我们邀 请了从事生态保护红线研究的部分学者撰文报道 生态保护红线的最新研究成果和进展, 希望引起广 大同仁的关注。

关于生态保护红线的定义, 不同学者、管理者 及公众的理解和认识不尽统一。根据《环境保护法》 (2014年修订版), 生态保护红线是依法在重点生态 功能区、生态环境敏感区和脆弱区等区域划定的严 格管控边界, 是国家和区域生态安全的底线(环境 保护部，2015)。国际上虽无“生态保护红线”一词， 但在自然生态保护地建设与管理方面有许多类似 的提法及分类体系。如世界自然保护联盟(IUCN) 推动的全球自然保护地建设、欧盟自然保护区网络 (Natura 2000)以及美国、日本等国家的生态保护地 (Ecological Protected Areas)、特别保育区(Special Areas of Conservation)、特殊保护地 (Special Protected Areas) 等都隐含有生态保护红线的含义 (Mascia \& Pailler, 2011; UNEP-WCMC, 2012)。生态 保护红线划定与国际上的系统保护规划(Systematic Conservation Planning) 有类似之处, 即通过最大限 度地保护特定尺度区域内的生态过程与功能, 合理 整合与优化现有的各类保护地, 识别保护空缺, 并 综合考虑保护目标、保护成本、管控方法等, 确定 需重点保护的对象, 以实现维护区域生态安全的最 终目标(Kukkala \& Moilanen, 2013)。

依据生态保护红线的科学内涵和我国生态保

\footnotetext{
“通讯作者 Author for correspondence. E-mail: gjx@nies.org
} 
护需求, 生态红线保护区主要保护三大功能:一是 保护重要生态功能区, 为经济社会可持续发展提供 生态支撑; 二是保护生态敏感区、脆弱区, 减缓与 控制生态灾害, 构建人居环境生态屏障; 三是保护 关键物种与生态系统, 维持生物多样性, 促进生物 资源的可持续利用(高吉喜, 2014)。相应地, 生态保 护红线体系可划分为重要生态功能区保护红线, 生 态敏感区、脆弱区保护红线, 以及生物多样性保护 红线三大类型。根据生态服务功能类型和生态敏感 性特征, 三大类型生态保护红线又可细分为若干小 类。需说明的是, 对不同地区和不同地域尺度, 保 护的类型和对象应有所不同。

如何划定生态保护红线, 是当前需要探究的重 要问题。生态保护红线的划定, 不是简单的拿来主 义, 将现有的重要/重点生态功能区、自然保护区、 风景名胜区等做一个简单的叠加, 而是需要在对区 域生态系统功能、生态敏感性等分别进行定量评估 的基础上, 依据评估单元生态功能的重要性、生态 敏感性的强弱以及对生态安全格局的空间重要性 等, 将最为重要与敏感的区域及当前的保护空缺区 纳入生态保护红线区。通过对不同类型生态保护红 线进行空间叠加, 形成生态保护红线的划定方案。 依据划定方案, 还需开展地面调查, 明确生态保护 红线地块分布范围, 核定边界, 使红线最终落地, 并需与国家和地方的各种规划相衔接, 与当地的实 际生态需求相吻合。由此可见, 生态保护红线划定 是一项复杂而艰巨的工作, 最终划定的具有精确边 界的生态保护红线区, 是维系国家和区域生态安全 的核心生态区域。

作为国家和区域安全的另一条“生命线”, 生态 保护红线划定只是第一步, 而能不能守得住、能不 能管得住是接下来面临的更为艰巨的挑战。在现有 各类生态保护地管理方面, 自然保护区、风景名胜 区、地质公园、饮用水水源地等均已发布实施相关 法律规定, 规定了生态环境保护的具体条款和要求 (高吉喜等, 2014)。生态保护红线作为一个新生事物, 尽管已经纳入国家立法, 生态红线划定工作也上升 到国家战略高度, 但与之相配套的产业环境准入标 准、人口与企业退出机制、自然资源资产产权和用 途管制、生态补偿、绩效考核等诸多政策导向尚未 完全明确。如何与现有各类生态保护地的管控措施 相衔接、如何处理好生态保护与经济发展之间的矛
盾、如何实施生态保护红线管控绩效考核制度等问 题都亟需解决。从目前国家生态保护红线的管控要 求和江苏、天津等省市的管控经验来看, 分级分类 管控是当前的可行之举: 分级是指根据保护对象的 严格性程度分为一级管控区和二级管控区，对应采 取不同严格程度的管控措施; 分类是指对各类型生 态保护红线和具体红线区块实施差别化精细管理 措施。需强调的是, 生态保护红线管控必须要考虑 现有管理体制, 对已出台并实施的各类生态保护法 律法规和管理办法，应继续严格遵守(燕守广等, 2014)。

总体而言, 对于生态保护红线的研究与实践目 前尚处于探索阶段, 为不断加强生态保护红线的理 论支撑，后续需在如下方面进行深入探讨：(1)基于 生态保护红线的生态安全格局研究。生态保护红线 是国家和区域生态安全的底线, 是构建生态安全格 局的生态源地。因此, 在生态保护红线划定的基础 上，可进一步构建生态廊道、关键生态节点等，共 同形成完整的国家和区域生态安全格局。(2)生态保 护红线区内生态系统服务的相互作用机理研究。明 晰生态系统服务产生的生态过程、相互关系及其驱 动因素, 为红线区内生态系统服务的发挥和优化管 理提供科学依据。(3)生态保护红线的生态安全阈值 研究。生态系统本身对于外界干扰有一定的抵抗力, 但若其生态质量下降到某种程度或外界胁迫因素 增大到某一程度, 可使区域生态安全受到严重威胁 (张艳芳和任志远, 2006)。因此, 如何评估生态保护 红线区的可承受能力或阈值对红线区的科学管理 具有重要意义。(4)生态保护红线的保护成效分析与 评估。生态保护红线划定后, 应在管理过程中科学 评价红线区保护发挥的生态效益及对经济社会产 生的生态价值, 从而为各级政府管理者的生态保护 成效考核提供科学依据。

生态保护红线的管控, 同样需要不断探索。下 一步的工作重点应包括: (1)形成协调统一的工作机 制。设立跨部门的生态保护红线划定领导小组和工 作组, 充分发挥各部门的主观能动性。各级政府应 将工作重心放在红线的边界落地和管控落地。(2) 制定科学完善的配套政策。为实施最为严格的生态 保护红线制度, 须尽快研究制定与生态保护红线划 定和管理相匹配的配套政策, 具体包括生态保护红 线管理办法、绩效考核办法和生态补偿办法等。 
建立天地一体化的监管体系。整合现有各类生态监 测技术手段与方法，建立国家生态保护红线天地一 体化监管平台, 加强生态监测、日常监控和定期评 估, 严密监控人为活动对红线的扰动。(4)提高对严 守生态保护红线的“再认识”。切实加大生态保护红 线体系的宣传教育力度, 促进各个阶层共同参与生 态保护红线划定与监管的积极性和主动性。尤其是 管理者更要认识到“绿水青山就是金山银山”, 消除 生态保护阻碍经济增长的顾虑, 将发展的视角和重 点向生态保护与经济协调发展转移。

综上所述, 生态保护红线战略的实施, 是我国 生态环境保护工作的一项制度创新, 是优化国土空 间开发, 构建科学合理生态安全格局的基础, 是推 进生态文明建设的重要举措。本期“生态保护红线 专题”包括5篇文章。刘冬等(2015)对国外生态保护 地体系进行了较为系统的梳理和总结, 并对比了我 国现有保护地体系存在的空缺及分类管理中存在 的问题, 希望有助于生态保护红线的管控规划和措 施的制定与实施。邹长新等(2015)对生态保护红线 类型划分与管控措施进行了系统阐述，并基于国家 关于生态保护红线管控的最新形势要求, 提出了分 级划定、分类管理的生态保护红线基本管控思路与 措施。刘军会等(2015)针对区域自然环境演变过程
中出现的土地沙化、水土流失和石漠化等生态问题, 开展了全国生态敏感性综合评价, 并结合政府相关 文件和已有研究成果, 在全国初步划定出了18 个生 态环境敏感区/脆弱区。张殷波等(2015)提出了我国 植物物种红线划定原则, 并以高精度的重点保护植 物分布数据库为基础, 基于热点地区和 $\mathrm{GAP}$ 分析的 理论和方法, 识别出了重点保护植物的关键分布区 域，划出了我国珍稀濒危植物的生态保护红线。徐 德琳等(2015)对基于生态保护红线构建生态安全格 局方面进行了初步探索，尝试将生态保护红线区作 为生态安全格局源地, 通过生态廊道、生态战略节 点构建等, 建立了涵盖重要生态功能保护格局、人 居环境安全格局、生物多样性维系格局的生态安全 格局体系。

对于生态保护红线的划定和管控来说，本期文 章只是管中窥豹, 希望藉此引发更多同仁的关注和 思考, 进一步丰富完善生态保护红线的理论体系和 实践经验，推进生态保护红线战略的实施。

文中引用的参考文献见附录1 (http://www.biodiversity-science.net/fileup/PDF/w2015-317-1.pdf))。

(责任编辑: 周玉荣)

\section{附录 Supplementary Material}

\section{附录1 参考文献}

http://www.biodiversity-science.net/fileup/PDF/w2015-317-1.pdf 


\section{附录1 参考文献}

Gao JX (高吉喜) (2014) Construction ideas of national ecological protection redline system. Environmental Protection (环境保护), 42(2-3), 18-21. (in Chinese)

Gao JX (高吉喜), Zou CX (邹长新), Wang LX (王丽霞) (2014) Drawing ecological protection redline to deepen environmental impact assessment. Environmental Impact Assessment (环境影响评价), (4), 11-14. (in Chinese)

Kukkala AS, Moilanen A (2013) Core concepts of spatial prioritisation in systematic conservation planning. Biological Reviews, 88, 443-464.

Li GJ (李干杰) (2014) Ecological Protection Redlineensuring national ecological safety lifeline. Qiu Shi (求是), (2), 44-46. (in Chinese)

Liu D (刘冬), Lin NF (林乃峰), Zou CX (邹长新), You GY (游广永) (2015) Development of foreign ecological protected areas and linkages to ecological protection redline delineation and management in China. Biodiversity Science (生物多样性), 23, 708-715. (in Chinese with English abstract)

Liu JH (刘军会), Zou CX (邹长新), Gao JX (高吉喜), Ma S (马苏), Wang WJ (王文杰), Wu K (吴坤), Liu Y (刘洋) (2015) Location determination of ecologically vulnerable regions in China. Biodiversity Science (生物多样性), 23, 725-732. (in Chinese with English abstract)

Lü YH (吕一河), Fu BJ (傅伯杰), Chen LD (陈利顶) (2006) Ecological rehabilitation: a theoretical analysis. Acta Ecologica Sinica (生态学报), 26, 3891-3897. (in Chinese with English abstract)

Mascia MB, Pailler S (2011) Protected area downgrading, downsizing, and degazettement (PADDD) and its conservation implications. Conservation Letters, 4, 9-20.

Ministry of Environmental Protection of the People's Republic of China (中华人民共和国环境保护部) (2015) The
Technical Manual of Ecological Protection Redline Demarcation.http://www.mep.gov.cn/gkml/hbb/bwj/201505 /t20150518_301834.htm (accessed 2015-5-18) (in Chinese)

United Nations Environment Programme-World Conservation Monitoring Center (UNEP-WCMC) (2012) Protected Planet Report 2012: Tracking Progress Towards Global Targets for Protected Areas. http://old.unep-wcmc.org/medialibrary/ 2012/09/14/eb3bb854/PPR2012_en.pdf (accessed 2012-9-15)

Xu DL (徐德琳), Zou CX (邹长新), Xu MJ (徐梦佳), You GY (游广永), Wu D (吴丹) (2015) Ecological security pattern construction based on ecological protection redlines. Biodiversity Science (生物多样性), 23, 740-746. (in Chinese with English abstract)

Yan SG (燕守广), Lin NF(林乃峰), Shen WS(沈渭寿) (2014) Delineation and protection of ecological red Lines in Jiangsu Province. Journal of Ecology and Rural Environment (生态 与农村环境学报), 30, 294-299. (in Chinese with English abstract)

Zhang YB (张殷波), Fu JX (傅靖轩), Liu YL (刘莹立), Bai F (白帆), Sang WG (桑卫国) (2015) Delimiting Protection Threshold Area of rare and endangered plants in China. Biodiversity Science (生物多样性), 23, 733-739. (in Chinese with English abstract)

Zhang YF (张艳芳), Ren ZY (任志远) (2006) Discussion of the ways to quantificational evaluation and threshold value of regional ecological security. Journal of Arid Land Resources and Environment (干旱区资源与环境), 20, 11-16. (in Chinese with English abstract)

Zou CX (邹长新), Wang LX (王丽霞), Liu JH (刘军会) (2015) Classification and management of ecological red lines in China. Biodiversity Science (生物多样性), 23, 716-724. (in Chinese with English abstract) 